00

\title{
Спектральные зависимости оптического поглощения иммобилизованного в пленке Родамина Б от концентрации ионов меди в воде
}

\author{
(С) И.Ю. Денисюк, Е.Н. Галашева, М.В. Успенская, М.И. Фокина
}

Университет ИТМО, 197101 Санкт-Петербург, Россия

e-mail: denisiuk@mail.ifmo.ru

Поступило в Редакцию 2020 г.

В окончательной редакции 2020 г.

Принято к публикации 2020 г.

Проведено исследование влияния концентрации ионов меди на спектр поглощения Родамина Б в молекулярной форме в спиртовом растворе и иммобилизованного в полимерной гидрогелевой пленке. Показана чувствительность системы к присутствию ионов меди в концентрации $0.1 \mathrm{mg} / 1$, достаточная для практического применения. Нерастворимость Родамина Б в воде при его иммобилизации в объеме фотополимеризующейся гидрогелевой пленки позволяет создать хемосенсор, стабильный при длительных экспозициях и способный чувствовать сверхмалые концентрации анализируемой примеси.

Ключевые слова: сенсор тяжелых металлов, Родамин Б, фотополимер, хемосенсор, медь, спектр поглощения.

DOI: $10.21883 /$ OS.2020.11.50185.140-20

\section{Введение}

Проблема загрязнения окружающей среды является одной из самых острых для современного мира, в связи с этим существует необходимость в контроле выбросов промышленных предприятий и определении содержания вредных веществ в природе. Особенно опасно загрязнение водоемов тяжелыми металлами, которые попадают в них в составе промышленных отходов, а также через грунтовые воды от полигонов. Попадая в организм человека с водой, тяжелые металлы могут вызывать интоксикацию, которая становится причиной серьезных заболеваний. Например, избыток меди может привести к хроническим заболеваниям дыхательных путей (бронхиальная астма), воспалению поджелудочной железы (острый панкреатит) и другим заболеваниям [1]. Поэтому при проведении мониторинга водоемов особое внимание уделяется определению содержания тяжелых металлов и выявлению источников их поступления.

На данный момент контроль проводят методами индуктивно-связанной плазмо-масс-спектрометрии, рентгеновской флуоресцентной спектроскопии, атомноабсорбционной спектрометрии. Эти методы имеют ряд преимуществ, таких как чувствительность и широкий спектр определяемых элементов, но им присущ и ряд недостатков: большие затраты на оборудование, транспортировку образцов, необходимость проведения анализов в лаборатории, длительность анализа. Таким образом, возникает потребность в разработке мобильного экспресс-метода, который позволит проводить анализ на содержание ионов тяжелых металлов непосредственно на месте предполагаемого загрязнения.
Одним из многообещающих решений является использование оптосенсора тяжелых металлов, введенного в полимерную матрицу. Работа сенсора основана на изменении оптических спектров поглощения и люминесценции комплексообразующего красителя при взаимодействии с ионами тяжелых металлов.

В работе [2] рассмотрено влияние ионов тяжелых металлов на Родамин Б, иммобилизованный на поверхности частиц каолина. В работе показана значительная зависимость величины поглощения и положения максимума спектра поглощения Родамина Б от типа и концентрации ионов тяжелого металла. Недостатком метода является необходимость измерения спектров диффузного отражения, поскольку иммобилизация Родамина Б реализована путем его осаждения на частицы каолина микронных размеров и образования диффузной среды.

Известны публикации, в которых рассмотрено изменение спектра поглощения Родамина при образовании комплекса с тяжелым металлом (свинец, ртуть) и показана высокая чувствительность метода [3]. Следовательно, основная задача, решение которой необходимо для создания сенсора, - иммобилизовать Родамин в молекулярном состоянии в матрице, проницаемой для воды и ионов, так, чтобы краситель сохранял молекулярное состояние при высокой концентрации в гидрогеле.

В настоящей работе проведено исследование влияния ионов меди на спектры Родамина Б, растворенного в спирте и иммобилизованного в полимерной гидрогелевой пленке. Для иммобилизации был выбран подход, ранее успешно использованный нами при введении ксиленового оранжевого в полимерный гель и описанный в работе [4]. 


\section{Условия и методы эксперимента}

Измерения спектров поглощения проводились на спектрофотометре UV-1800 Shimadzu (Япония). Измерения проводились как в растворе, так и в твердой гелеобразной пленке и были направлены на выяснение изменений спектра поглощения Родамина Б в присутствии малых концентраций ионов меди.

Исследование влияния малых концентраций меди на Родамин Б в растворе выполнялось по следующей методике. Приготовлялись два раствора в изопропаноле Родамина Б (фирмы Эпсилон) в концентрации $1 \mathrm{mg} / 1$ и $\mathrm{CuCl}_{2} \times 2 \mathrm{H}_{2} \mathrm{O}$ (Aldrich, № 1.02733) в концентрациях по меди $0.1,0.3,0.5,1 \mathrm{mg} / 1$. Раствор Родамина Б заливался в измерительную кювету спектрофотометра и к нему добавлялся раствор хлорида меди.

Для исследования влияния меди на спектр иммобилизованного Родамина Б использована гидрогелевая матрица, состав которой был разработан нами ранее [4]. Основные компоненты гидрогеля: смесь фотополимеризующихся акрилатов с поперечной сшивкой и водорастворимый полимер - полиэтиленгликоль, связанный в сетке акрилатов. Как было показано ранее [4], композит позволяет формировать пленки при фотополимеризации, а при погружении в воду разбухает в 3 раза за $2-3 \mathrm{~min}$, обеспечивая транспорт ионов металла.

Гидрогелевая пленка с иммобилизованным в ней Родамином Б была получена следующим способом. Смешивались полиэтиленгликоль (PEG, Aldrich № 94646), триметилолпропан этоксилат $(1 \mathrm{EO} / \mathrm{OH})$, метиловый эфир диакрилат (ТМР, Aldrich № 415871) и 2-карбоксиэтил акрилат (2-Car, Aldrich № 552348) в соотношении по массе 2-Car:TMP:PEG=64:7:29. Так как PEG - твердый полимер, он растворялся в смеси мономеров при ультразвуковой активации. В полученную смесь добавлялся раствор Родамина Б в изопропиловом спирте (0.1 wt.\%). После испарения спирта в смесь добавлялся инициатор УФ полимеризации 2,2-диметокси-2-фенилацентофенон (Aldrich 19,611-8) в количестве $0.1 \mathrm{wt} . \%$. Под действием УФ излучения проводилась фотополимеризация с получением твердой пленки толщиной порядка $300 \mu \mathrm{m}$.

Для измерения спектра поглощения пленка погружалась на $5 \mathrm{~min}$ в $100 \mathrm{ml}$ дистиллированной воды для набухания, затем измерялся исходный спектр и далее добавлялся водный раствор $\mathrm{CuCl}_{2} \times 2 \mathrm{H}_{2} \mathrm{O}$ с прогрессивно увеличивающейся концентрацией так, чтобы измерения с увеличением концентрации меди проводились на одном образце.

\section{Экспериментальные результаты и их обсуждение}

Влияние малых концентраций ионов меди на спектр Родамина Б в растворе в изопропиловом спирте показано на рис. 1. Здесь видно, что добавление меди не

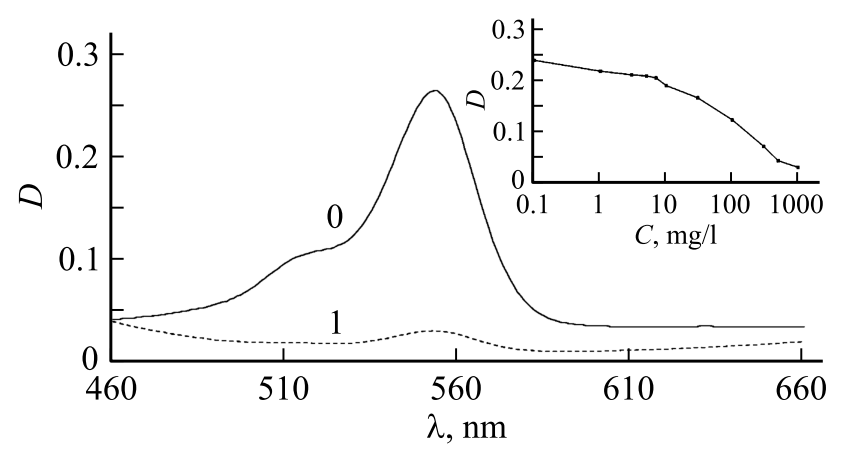

Рис. 1. Спектр поглощения спиртового раствора Родамина Б в концентрации $1 \mathrm{mg} / 1$ без меди (0) и в присутствии $1 \mathrm{mg} / 1$ ионов меди (1). Врезка: зависимость оптической плотности раствора Родамина Б на длине волны $553 \mathrm{~nm}$ от концентрации ионов меди.

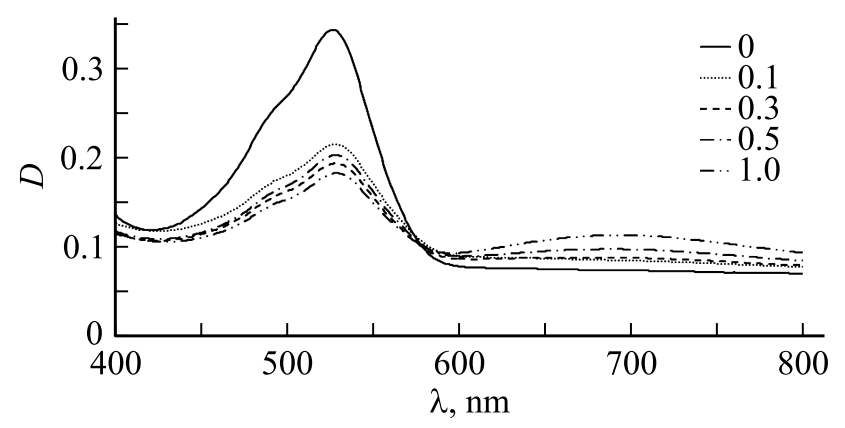

Рис. 2. Спектр поглощения полимерной пленки с Родамином Б, измеренный после погружения в дистиллированную воду (0) и далее в растворы хлорида меди с концентрацией ионов меди $0.1,0.3,0.5,1 \mathrm{mg} / \mathrm{l}$.

приводит к появлению каких-либо новых максимумов, ассоциируемых с образованием комплекса. Положение максимума поглощения Родамина Б сохраняется неизменно на длине волны $553 \mathrm{~nm}$, а его величина снижается. Спектральные изменения характеризуются оптической плотностью на длине волны максимума поглощения раствора красителя; на врезке представлена ее зависимость от концентрации ионов меди в растворе.

Приведенные экспериментальные данные показывают значительную чувствительность поглощения Родамина Б к концентрации ионов меди.

На рис. 2 приведены результаты измерения спектра поглощения Родамина Б, иммобилизованного в гидрогелевой фотополимеризующейся матрице, при различных значениях концентрации ионов меди. Исходя из результатов, представленных на рис. 2, видно, что Родамин Б, иммобилизованный в гидрогеле в водной среде, реагирует на присутствие ионов меди приблизительно в той же степени, как и в растворе. Форма спектра Родамина Б также соответствует спектру раствора. Следовательно, гидрогелевая пленка, не растворимая в воде, содержащая иммобилизованный в ней индикатор Родамин Б, также не растворимый в воде и не вымывающийся из плен- 
ки, может быть использована как сенсор ионов меди, возможно, и других тяжелых металлов, содержание которых можно определять фотометрическим методом по изменению величины поглощения красителя при длине волны $553 \mathrm{~nm}$.

Проведенные исследования показывают чувствительность метода к меди в концентрации $0.1 \mathrm{mg} / 1$, которая в 10 раз ниже ПДК по меди - $1 \mathrm{mg} / \mathrm{l}$ [5].

\section{Выводы}

В работе исследованы спектры поглощения спиртового раствора Родамина Б и фотополимеризующейся гидрогелевой пленки с иммобилизованным в ней красителем в зависимости от концентрации ионов меди. Установлено, что поглощение Родамина Б на длине волны максимума $553 \mathrm{~nm}$ в обоих случаях снижается c повышением концентрации меди. Процесс комплексообразования Родамина Б с медью, за счет которого происходит изменение спектра поглощения, а также нерастворимость иммобилизованного в гидрогелевой пленке красителя в воде позволят создать на его основе хемосенсор с чувствительностью $0.1 \mathrm{mg} / 1$ меди в воде.

\section{Конфликт интересов}

Авторы заявляют, что у них нет конфликта интересов.

\section{Список литературы}

[1] Черных Н.А., Баева Ю.И. // Вестник РУДН. Серия: Экология и безопасность жизнедеятельности. 2004. № 1. C. $125-134$.

[2] Рамазанов А.Ш. // Аналитика и контроль. 2015. № 3. C. 259-267. doi 10.15826/analitika.2015.19.3.002

[3] Kim H.N., Lee M.H., Kim H.J., Kim J.S., Yoon J. // Chem. Soc. Rev. 2008. V. 37. N 8. P. 1465-1472. doi 10.1039/b802497a

[4] Денисюк И.Ю., Игнатьева Ю.А., Успенская М.В., Фокина М.И. // Опт. и спектр. 2019. Т. 126. В. 6. С. 748-750.

[5] Гигиенические нормативы ГН 2.1.5.2280-07 „Предельно допустимые концентрации (ПДК) химических веществ в воде водных объектов хозяйственно-питьевого и культурнобытового водопользования“ 2007. 